\title{
A clinical prediction model did well in diagnosing paediatric group A $\beta$-haemolytic streptococcal pharyngitis
}

Attia MW,Zaoutis T, Klein JD, et al. Performance of a predictive model for streptococcal pharyngitis in children. Arch Pediatr Adolesc Med 2001 Jun;155:687-91.

\section{QUESTION: In children with suspected group A $\beta$-haemolytic streptococcal (GABHS) pharyngitis, how well does a prediction model predict a positive throat culture?}

\section{Design}

1 year validation of a previously derived prediction model.

\section{Setting}

Paediatric emergency department and 2 paediatric outpatient clinics in Wilmington, Delaware, USA.

\section{Patients}

587 children (mean age 6.8 y, $51 \%$ girls) who had signs and symptoms of acute pharyngitis. Exclusion criteria were antibiotic treatment within 5 days of enrollment.

\section{Description of prediction guide}

During the clinical evaluation, the examining physician recorded 4 variables from the tested model: cervical lymphadenopathy, tonsillar swelling (2 category severity scale: absent or mild and moderate or severe), coryza, and scarletiniform rash (present or absent). 2 tonsillopharyngeal specimens were collected for each patient for serotyping (diagnostic standard) and a rapid streptococcal antigen detection test. Furthermore, the physician made a subjective probability estimate for a GABHS-positive throat culture result (11-point scale: 0 $=$ most unlikely and $10=$ extremely likely).

\section{Main outcome measures}

A performance score was calculated for the prediction model ranging from 0 to 5 , with higher scores indicating more severe indications of the clinical variables. Sensitivity, specificity, likelihood ratios, and post-test probability were calculated for cutoff points of the performance score.

Source of funding: Nemours Research Programs.

For correspondence: Dr M WAttia,

Department of

Pediatrics, Alfred I.

duPont Hospital for

Children, 1600

Rockland Road,

Wilmington, $D E$

19803, USA.

mattia@nemours.org

\section{Main results}

218 children (37\%) had positive culture results for GABHS. The prediction model did better than the physicians' probability estimates and was comparable to the rapid antigen detection test (table). The model did not differ in performance according to setting (emergency department $v$ outpatient clinic) or study period (in season [January to March] $v$ off season [April to December]).

Validation at 1 year of a prediction model for diagnosing paediatric group A $\beta$-haemolytic streptococcal pharyngitis*

\begin{tabular}{|c|c|c|c|c|c|}
\hline Assessment tool & $\begin{array}{l}\text { Sensitivity } \\
(95 \% \mathrm{Cl})\end{array}$ & Specificity (Cl) & +LR & -LR & $\mathrm{PP}(\mathrm{Cl})$ \\
\hline \multicolumn{6}{|l|}{ Prediction model† } \\
\hline Score $=0$ & $99 \%(96$ to 100$)$ & $5 \%$ (3 to 7 ) & 1.0 & 0.2 & $0.12(0.02$ to 0.3$)$ \\
\hline Score 1 to 3 & $81 \%$ (75 to 86$)$ & $7 \%(5$ to 10$)$ & 0.9 & 2.5 & $0.36(0.3$ to 0.4$)$ \\
\hline Score $\geqslant 4$ & $17 \%(13$ to 27$)$ & $98 \%(94$ to 99$)$ & 5.9 & 0.8 & $0.79(0.6$ to 0.9$)$ \\
\hline $\begin{array}{l}\text { Subjective score } \\
6 \text { to } 10\end{array}$ & $75 \%(68$ to 80$)$ & $56 \%$ (51 to 62$)$ & 1.7 & 0.5 & $0.52(0.5$ to 0.6$)$ \\
\hline Rapid antigen test & $86 \%(81$ to 91$)$ & $91 \%(87$ to 94$)$ & 9.6 & 0.1 & $0.85(0.8$ to 0.9$)$ \\
\hline
\end{tabular}

*Abbreviations and diagnostic terms defined in glossary.

†Higher scores of the prediction model equal more severe indications of the clinical variables.

\section{Conclusion}

In children with suspected group A $\beta$-haemolytic streptococcal pharyngitis, a clinical prediction model predicted a positive throat culture as well as a rapid antigen detection test and better than subjective estimation by physicians.

\section{COMMENTARY}

The study by Attia $e t$ al shows that clinicians are not good at estimating the presence of GABHS pharyngitis in symptomatic children (only about $50 \%$ of those subjectively estimated as being "strep positive" had a positive GABHS throat culture result). The simple predictive model described here is much more accurate (post-test probability of 79\%) and almost as good as a rapid antigen test (post-test probability of $85 \%$ ). Such results should encourage us to use the model for deciding on management: it is easy to use, quick, and cheaper than the rapid antigen test. However, one interesting finding from this well-conducted study was the high culture rate in the control group (children with no sore throat being seen for other reasons; $15 \%$ ) compared with that in children with symptoms $(37 \%)$. In children with a strep-positive culture result, distinguishing carrier state from infection remains difficult. This is a weakness of the study, unlike the study by Dagnelie $e t a l^{\prime}$ in which a better measure of infection - a 4-item model (cough, exudate on the throat, fever, and neck lymph nodes) - was also compared with anti-streptolysin-O titers.

But let us step back a moment. Why is accurate diagnosis of streptococcal sore throat and its differentiation from other causes of sore throat important? It enables us to treat "strep throat" with antibiotics to prevent acute rheumatic fever (ARF), acute glomerulonephritis, and suppurative complications, and to shorten the illness or decrease its severity. But in many areas, ARF is so rare that treating it might create as much risk from the antibiotics as there is from the disease, and the symptomatic benefits of antibiotics are so modest ${ }^{2}$ that alternative, non-antibiotic treatment ${ }^{3}$ may be as good if not better.

Perhaps we should think carefully about what we intend to do once we diagnose GABHS before worrying too much about how to diagnose it. Only in clinical settings where ARF is common (eg, developing countries) ${ }^{4}$ or in patients with special concerns for symptomatic relief, should we concern ourselves with deciding the cause. After all, sore throats get better spontaneously.

Chris B Del Mar, MB, BChir University of Queensland, Herston, Queensland, Australia

1 Dagnelie CF, Bartelink ML, van der Graaf Y, et al. Towards a better diagnosis of throat infections (with group A betahaemolytic streptococcus) in general practice. Br J Gen Pract 1998;48:959-62.

2 Del Mar CB, Glasziou PP, Spinks AB. Antibiotics for sore throat. Cochrane Database Syst Rev 2000;(2):CD000023.

3 Thomas M, Del Mar C, Glasziou P. How effective are treatments other than antibiotics for acute sore throat? $\mathrm{Br} J$ Gen Pract 2000;50:817-20.

4 Berman S. Otitis media in developing countries. Pediatrics 1995;96:126-31. 